\title{
BEYOND BLOOM'S: USEFUL CONSTRUCTS FOR DEVELOPING GRADUATE ATTRIBUTE INDICATORS
}

\author{
McCahan, S.; Romkey, L. \\ Faculty of Applied Science and Engineering, University of Toronto, Ontario Canada \\ mccahan@mie.utoronto.ca
}

\section{INTRODUCTION}

What do we want our students to learn from an experience? This is the central question that underpins learning objectives. Learning objectives attempt to describe the manifestations of learning that we would like to see by the end of a learning experience (e.g. a course or a learning module). Traditionally areas of knowledge that are the target of learning objectives are described as domains. Typically knowledge is described as cognitive, affective, or psychomotor and there are other domains such as interpersonal ${ }^{1-4}$. The domain describes the nature of the learning. Has the student learned a new cognitive process, or learned to care about something new? The organization of learning into these domains helps us to make sense of the types of knowledge that our students are learning. A domain is like a country, it defines a piece of the knowledge landscape.

A taxonomy of learning attempts to map that landscape. It creates categories that describe ways of knowing. Just as a map describes the landscape using categories (e.g. roads, parks, towns), a taxonomy categorizes ways of knowing so that we can better define the manifestation of learning that we want our students to achieve. Most taxonomies are meant to be thorough maps of one domain. For example Bloom's taxonomy describes ways of knowing within the cognitive process domain ${ }^{1}$. It attempts to categorize all of the different levels of learning in this domain. When Anderson and Krathwohl later updated Bloom's taxonomy they added a second dimension, the knowledge dimension, which breaks apart the domain into 4 parts: factual knowledge, conceptual knowledge, procedural knowledge, and metacognitive knowledge ${ }^{5}$. Their taxonomy applies the same levels of learning (i.e. cognitive processes) to each of these four pieces of the domain. Bloom's (or Anderson's) do not describe everything that a student should learn. They are only meant to describe one type of learning: cognitive process. Other taxonomies map other domains and some taxonomies cut across domains.

\section{DEVELOPMENT OF AN ALTERNATIVE MODEL}

This is important because many of the learning objectives we would like to achieve to meet the CEAB Graduate Attributes are not located in the cognitive domain exclusively. In fact, educational developers such as Fink have made the point that to be significant, learning must extend beyond the cognitive process domain ${ }^{6}$. Fink has proposed a taxonomy that cuts across traditional domain boundaries, and other researchers have also proposed models that do not neatly fall into any one domain. One of these, Miller's pyramid, was developed for clinical practice in medicine ${ }^{7}$.

Miller suggested a pyramid to describe the learning in clinical practice (Figure 1). Miller's pyramid was originally developed without reference to domains or other taxonomies. However, people have made the connection between the levels of Miller's pyramid and learning domains $^{8}$. It has been suggested that Miller's pyramid cuts across the affective, psychomotor and cognitive domains. Learning at each of the three levels involves aspects from all three of these domains. Given the similarities between aspects of learning in clinical practice and aspects of the practical learning in engineering, it would be useful to have a similar taxonomy for engineering practice.

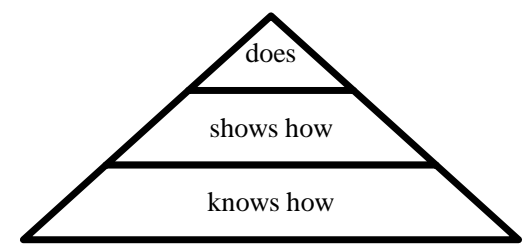

Figure 1: Miller's Pyramid.

We suggest that an adaptation of Miller's pyramid for the learning of engineering practice (Table 1) would be a useful addition to the tools available for describing learning outcomes. It could help to describe engineering practices such as problem solving, the use of appropriate methods and tools; For example the types of methods and tools used in the design process. This might be called a taxonomy of practice, or a process skills taxonomy. It is meant to describe the learning of processes, or procedural knowledge. The taxonomy moves from a low level, being able to recall the sequence of steps in a process, to a high level, appropriate practice in an authentic context. Like Miller's pyramid, it cuts across several domains. The lower levels are characteristically cognitive, and the upper levels share some qualities from the psychomotor and affective domains. Throughout this taxonomy we expect a student to develop an increasing degree of caring (affective and interpersonal domain) about the quality of their practice. While much of engineering practice is more cognitively based compared to clinical practice (e.g. the skill of drawing blood), it shares with medicine the interpersonal skills aspect. Both professions work with people to meet the needs of society. Both are concerned with safety and well-being. This means that the practice of these professions must integrate learning across the traditional domains, and effective practice must involve the bringing together of cognitive skills in the context of working with and for people. Attitudes toward safety and the health and welfare of the public must pervade our practice. In addition the attention to the quality of our work and a commitment to quality should become part of natural practice.

Table 1. Adaptation of Miller's Pyramid to engineering practice

\begin{tabular}{|l|l|}
\hline $\begin{array}{l}\text { Miller's } \\
\text { Pyramid }\end{array}$ & Engineering Practice levels \\
\hline Knows how & $\begin{array}{l}\text { Describe - be able to describe the process or practice. } \\
\text { List the steps in the sequence. } \\
\text { Verbs: recall, state, list steps }\end{array}$ \\
\cline { 2 - 3 } & $\begin{array}{l}\text { Comprehend -- be able to explain the process or } \\
\text { practice; explain what methods could be used and why } \\
\text { they are appropriate. } \\
\text { Verbs: identify, explain, illustrate }\end{array}$ \\
\hline Shows how & $\begin{array}{l}\text { Demonstrate - be able to demonstrate the process or } \\
\text { practice when cued. Demonstrate caring (e.g. caring } \\
\text { w.r.t. safety and quality of work). } \\
\text { Verbs: demonstrate, show, implement }\end{array}$ \\
\cline { 2 - 3 } & $\begin{array}{l}\text { Select and Combine - be able to select appropriate } \\
\text { processes or practices and combine them. Select } \\
\text { processes that show caring. } \\
\text { Verbs: choose, blend, adapt, modify, organize, } \\
\text { demonstrate, adjust }\end{array}$ \\
\hline Does & $\begin{array}{l}\text { Naturalize -- be able to use a variety of processes as a } \\
\text { natural part of practice; select, use, and adapt processes } \\
\text { in authentic situations. Caring is a natural part of the } \\
\text { person's authentic practice. } \\
\text { Verbs: is observed, performs, executes }\end{array}$ \\
\hline
\end{tabular}

REFERENCES

1. . Bloom BS. Taxonomy of Educational Objectives, Handbook I: The Cognitive Domain. New York, NY: David McKay Co Inc., 1956.

2. Krathwohl, DR, Bloom, BS, \& Masia, BB. Taxonomy of Educational Objectives, the Classification of Educational Goals. Handbook II: Affective Domain. New York, NY: David McKay Co., Inc., 1973. 3. R. H. Dave, as reported in R. J. Armstrong et al., Developing and Writing Behavioral Objectives. Tucson, AZ: Educational Innovators Press, 1970.

4. C. Vinson. Learning Domains and Delivery of Instruction. [Online]. Available: http://pixel.fhda.edu/hybrid/learning_domain.html.

5. Anderson, LW; Krathwohl, DR. A Taxonomy for Learning, Teaching, and Assessing. New York, Addison Wesley Longman, Inc., 2001.

6. Fink, LD. Creating Significant Learning Experiences. San Francisco CA, Jossey-Bass, 2003.

7. Miller, GE. Acad. Med., 1990; 65: 63-67.

8. Cheek, B. GP-Training.net. [Online]. Available at http://www.gptraining.net/training/educational_theory/adult_learning/miller.htm 